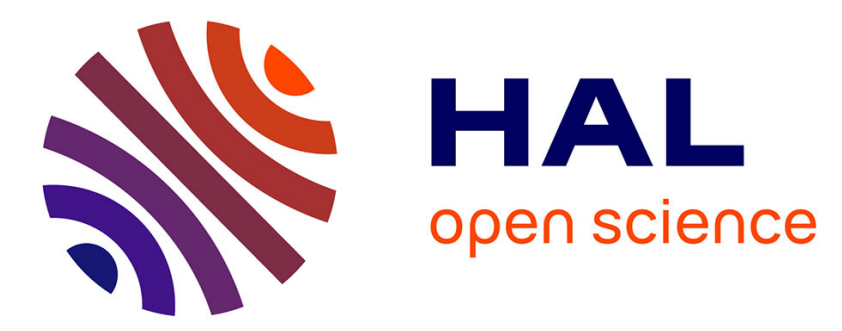

\title{
Transmural stretch-dependent regulation of contractile properties in rat heart and its alteration after myocardial infarction
}

Olivier Cazorla, Szabolcs Szilagyi, Jean-Yves Le Guennec, Guy Vassort, Alain Lacampagne

\section{To cite this version:}

Olivier Cazorla, Szabolcs Szilagyi, Jean-Yves Le Guennec, Guy Vassort, Alain Lacampagne. Transmural stretch-dependent regulation of contractile properties in rat heart and its alteration after myocardial infarction. FASEB Journal, 2005, 19 (1), pp.88-90. 10.1096/fj.04-2066fje . hal-01824390

\section{HAL Id: hal-01824390 \\ https://hal.umontpellier.fr/hal-01824390}

Submitted on 27 Jun 2018

HAL is a multi-disciplinary open access archive for the deposit and dissemination of scientific research documents, whether they are published or not. The documents may come from teaching and research institutions in France or abroad, or from public or private research centers.
L'archive ouverte pluridisciplinaire HAL, est destinée au dépôt et à la diffusion de documents scientifiques de niveau recherche, publiés ou non, émanant des établissements d'enseignement et de recherche français ou étrangers, des laboratoires publics ou privés. 
The FASEB Journal express article10.1096/fj.04-2066fje. Published online October 21, 2004.

\title{
Transmural stretch-dependent regulation of contractile properties in rat heart and its alteration after myocardial infarction
}

\author{
Olivier Cazorla, Szabolcs Szilagyi, Jean-Yves Le Guennec,* Guy Vassort, and \\ Alain Lacampagne
}

INSERM U-637, CHU Arnaud de Villeneuve, 34295 Montpellier, France

Corresponding author: Guy Vassort, INSERM U-637, CHU Arnaud de Villeneuve, 34295

Montpellier, France. E-mail: vassort@montp.inserm.fr

*Present address: EMI-U 0211, Faculté de médecine, 37032 Tours, France

\section{ABSTRACT}

The "stretch-sensitization" response is essential to the regulation of heart contractility. An increase in diastolic volume improves systolic contraction. The cellular mechanisms of this modulation, the Frank-Starling law, are still uncertain. Moreover, their alterations in heart failure remains controversial. Here, using left ventricular skinned rat myocytes, we show a nonuniform stretch-sensitization of myofilament activation across the ventricular wall. Stretch-dependent $\mathrm{Ca}^{2+}$ sensitization of myofilaments increases from sub-epicardium to sub-endocardium and is correlated with an increase in passive tension. This passive tension-dependent component of myofibrillar activation is not associated with expression of titin isoforms, changes in troponin I level, and phosphorylation status. Instead, we observe that stretch induces phosphorylation of ventricular myosin light chain 2 isoform (VLC2b) in sub-endocardium specifically. Thus, VLC2b phosphorylation could act as a stretch-dependent modulator of activation tuned within normal heart. Moreover, in postmyocardial infarcted rat, the gradient of stretch-dependent $\mathrm{Ca}^{2+}$ sensitization disappears associated with a lack of VLC2b phosphorylation in sub-endocardium. In conclusion, nonuniformity is a major characteristic of the normal adult left ventricle (LV). The heterogeneous myocardial deformation pattern might be caused not only by the morphological heterogeneity of the tissue in the LV wall, but also by the nonuniform contractile properties of the myocytes across the wall. The loss of a contractile transmural gradient after myocardial infarction should contribute to the impaired LV function.

Key words: $\mathrm{Ca}^{2+}$ sensitization $\bullet$ Frank-Starling law $\bullet$ ventricular myocytes $\bullet$ myosin light chain 2 - heart failure

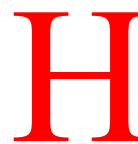

eart muscle has the property to develop positive inotropism in response to an increase in end-diastolic ventricular volume. This phenomenon, known as the Frank-Starling law, originates from cell adaptation to stretch involving a sarcomere length (SL) dependence of the $\mathrm{Ca}^{2+}$ sensitivity of myofilament activation (1). The mechanisms that underlie this intrinsic property may involve a length-dependent increase in the affinity of the regulatory site of troponin 
$\mathrm{C}$ for $\mathrm{Ca}^{2+}$. There is also substantial evidence that stretch reduces interfilament lattice spacing, increasing the probability of a myosin head to bind actin (2). However, we previously observed in intact isolated cardiomyocytes that active tension correlated to diastolic properties rather than to SL per se (3). We showed on isolated cardiomyocytes that reducing passive tension by degrading titin with a mild trypsin digestion (4) or by modulating the prehistory of stretch (5) decreases $\mathrm{Ca}^{2+}$ sensitivity in proportion to titin-based passive tension. Combining the differences in titin isoform expression in bovine atrium and ventricular strips with variation of the stretch prehistory revealed that the SL-dependent increases in $\mathrm{Ca}^{2+}$ sensitivity of force and maximal active force were most pronounced in myocardium with high titin-based passive force (6). Recent studies proposed that titin-based passive tension could promote actomyosin interaction by reducing the interfilament lattice spacing $(5,6)$. Differential coexpression of titin isoforms influences cellular stiffness but also the degree of interfilament lattice spacing changes. conferring a modulator role in the Frank-Starling mechanism on titin. Other studies concluded that length-dependent activation in the heart cannot be entirely explained by alterations in interfilament lattice spacing and preferred a central role of troponin I (TnI) in cardiac myofilament activation $(7,8)$.

Although cardiac contractility is altered under various pathological conditions, changes of the Frank-Starling properties are still controversial. In human heart failure, the Frank-Starling relationship has been reported to be normal (9) or lost in accordance with a smaller increase in the $\mathrm{Ca}^{2+}$ sensitivity of the myofibrils after stretch (10). Similar alterations of contractility, as a consequence of remodeling of the whole heart were described in a rat model of postmyocardial infarction (PMI) (11). However, the latter authors did not observe any perturbation during shortening measurements on unloaded isolated PMI cardiomyocytes. Others reported variable effects of heart failure on myofibrillar $\mathrm{Ca}^{2+}$ sensitivity depending on the study, that is, either a decrease in PMI porcine preparations, PMI and spontaneous hypertensive cardiomyocyte rat models of heart failure, or no change in failing rats, or an increase was observed in human dilated cardiomyopathy and its canine model (for review, see ref 12). Note that these studies were performed at only one SL. Heart failure was also associated with changes in the distribution and content of myocardial contractile proteins, including a decrease in myosin light chain (MLC) content in human chronic heart failure (13). Furthermore, several experimental works $(14,15)$ but not all (16) reported a reduced level of MLC2 phosphorylation in heart failure known to be associated with reduced $\mathrm{Ca}^{2+}$ sensitivity of the contractile proteins.

Cardiomyocytes do not present homogeneous behavior within the whole heart, and their alterations during pathologies differ with their localization. This has been particularly documented for the electrical properties of cardiomyocytes. Sub-endocardial (ENDO) cells exhibit a longer action potential than sub-epicardial (EPI) cells. This gradient, abolished in rat models of hypertrophy induced by aortic stenosis or of heart failure after myocardial infarction, is mostly due to a reduction of the transient outward $\mathrm{K}^{+}$current (Ito) in the epicardium (17). Regarding the contractile properties, we previously reported in intact ventricular myocytes of various species a gradient of cellular stiffness across the ventricular wall (18). In addition, according to their location in the wall, the cells function over different ranges of SL-active tension relationships despite similar calcium transients, suggesting structural differences within the contractile machinery and/or different length-signaling pathways (18).

The aim of the present study was to determine whether in skinned cardiomyocytes such a gradient of passive mechanical properties across the ventricular wall was observable and whether 
it was concomitant with a gradient of active properties. We also sought to determine whether such a gradient would be altered in a postmyocardial infarction model of cardiomyopathy.

\section{MATERIALS AND METHODS}

\section{Experimental myocardial infarction}

Male Wistar rats (180-220 g) were subjected to coronary artery ligature to produce PMI rats (17). In brief, rats were anesthetized (with pentobarbital, $60 \mathrm{mg} / \mathrm{kg}$ ) and ventilated. Shamoperated animals were subjected to the same surgical operation without tightening the coronary ligature. Animals were killed 14 wk postligature. Scar size was $\sim 25 \%$ of the left ventricular free wall area, and necrosis was transmural. Heart weight/body weight ratio $(\mathrm{mg} / \mathrm{g})$ was significantly increased from $2.9 \pm 0.5$ in sham $(n=7)$ to $3.8 \pm 0.4$ in PMI $(n=16)$ rats. Cells isolated from PMI rats were hypertrophied (cell width: $25 \pm 1$ and $28 \pm 1 \mu \mathrm{m}, n=40$ and 30 cells in sham and PMI, respectively). Pressure/volume relationships established on perfused hearts showed a $41 \%$ decrease in peak systolic pressure in PMI rats relative to the sham group (data not shown). Hemodynamic measurements performed on another series of animals demonstrated a significant increase in end-diastolic pressure from $2.5 \pm 0.5$ to $17.1 \pm 13.5 \mathrm{~mm} \mathrm{Hg}$ (in 9 sham and $9 \mathrm{PMI}$, respectively).

\section{Myocyte preparation}

Ventricular myocytes were isolated by mechanical dissociation as described previously with some modifications (19). In brief, rats were anaesthetized by intraperitoneal injection of pentobarbital $(0.2 \mathrm{~g} / 100 \mathrm{~g})$. The heart was perfused retrogradely $\left(3 \mathrm{ml} . \mathrm{min}^{-1}\right)$ with a $\mathrm{Ca}^{2+}$-free Hanks-HEPES buffered solution for $5 \mathrm{~min}$ at room temperature containing in $\mathrm{mM}$ : $\mathrm{NaCl} 117$, $\mathrm{KCl}$ 5.7, $\mathrm{NaHCO}_{3}$ 4.4, $\mathrm{KH}_{2} \mathrm{PO}_{4}$ 1.5, $\mathrm{MgCl}_{2}$ 1.7, HEPES 21, glucose 11, taurine 20, $\mathrm{pH} 7.2$, adjusted with $\mathrm{NaOH}$ and bubbled with $100 \% \mathrm{O}_{2}$. 2,3-Butanedione monoxime $(15 \mathrm{mM})$ was also added to the buffer to inhibit contraction and to preserve energetic stocks. Then, the heart was preskinned by perfusing relaxing solution (for composition, see below) containing $1 \%$ Triton X100 and protease inhibitors (0.5 mM PMSF, $0.04 \mathrm{mM}$ leupeptin, and 0.01 mM E64) for 7-10 min. Right ventricle and PMI fibrotic tissue were discarded. Several left EPI and ENDO strips (8 $\mathrm{mm}$ long, $2 \mathrm{~mm}$ wide, $1 \mathrm{~mm}$ thick) were dissected from the same heart and frozen in liquid nitrogen for biochemistry or further skinned $10 \mathrm{~min}$ at $4{ }^{\circ} \mathrm{C}$ in relaxing solution containing $1 \%$ Triton X-100 for mechanical experiments. The strips were then placed in fresh ice-cold relaxing solution and mechanically disrupted at 11,000 rpm for 2-3 s (Polytron PT45-80 with a PTA 10TS shaft, KINEMATICA AG, Switzerland), resulting in a suspension of small clumps of myocyte-sized preparations and cell fragments. The homogenized tissue was filtered and centrifuged at $1000 \mathrm{rpm}$ for $1 \mathrm{~min}$ at $4^{\circ} \mathrm{C}$. The pellet containing the myocytes was skinned in $0.3 \%$ Triton X-100 solution for 6 min to remove remaining sarcolemma membranes and then was extensively washed in relaxing solution. To prevent degradation, all solutions contained protease inhibitors (see above). Cells were kept on ice and used within the day. Some cells were used immediately after cell isolation for mechanical experiments; others were solubilized for gel electrophoresis. 


\section{Experimental solutions}

$\mathrm{Ca}^{2+}$-activating solutions were prepared daily by mixing relaxing (pCa 9.0) and maximal activating ( $\mathrm{pCa} 4.5$ ) solutions (20). The relaxing and activating buffers contained (in mmol/1): phosphocreatine 12, imidazole 30, free $\mathrm{Mg}^{2+}$ 1, EGTA 10, $\mathrm{Na}_{2} \mathrm{ATP} 3.3$, and dithiothreitol 0.3 with pCa 9.0 (relaxing solution) and pCa 4.5 (maximal activating solution), $\mathrm{pH} 7.1$ adjusted with acetic acid (osmolarity $280 \mathrm{mOsm}$ ). Sufficient potassium acetate was added to adjust ionic strength to $180 \mathrm{mmol} / \mathrm{l}$.

\section{Single cell SL and force measurements}

The procedure of cell attachment was previously reported (20). The skinned myocyte was attached at either end to a piezoresistive strain gauge (model AE 801, SensoNor a.s., Horten, Norway; $500 \mathrm{~Hz}$ unloaded resonant frequency) and a stepper motor driven micromanipulator (MP-285, Sutter Instrument Company, Novato, CA) with thin glass needles and optical glue (NOA 63, Norland Products, North Brunswick, NJ) that was polymerized by UV illumination for 3 min. SL was determined online throughout the experiment at $50 \mathrm{~Hz}$ by using a fast Fourier transform algorithm (FFT) on the video images of the attached cell. The cell was positioned at the tip of a conical microcapillary that received the outlet of ten microcapillaries connected to 5$\mathrm{ml}$ syringes. Solutions were selected with clips allowing flowing or not of the different solutions (flow rate $200 \mu 1 . \mathrm{min}^{-1}$ ). Force was normalized to cell cross-section area using the width of the cell measured on the video monitor and an estimated value of $2 / 3$ of cell width for the thickness. This ratio was determined on a population of myocytes loaded with membrane fluorescent indicator di-4-ANEPPS ( $5 \mu \mathrm{M}$ for $5 \mathrm{~min}$, Molecular Probes, Eugene, OR) to visualize the surface membrane with a laser scanning confocal microscope (Zeiss LSM510). Cell thickness was measured by Z-axis scanning through the upper and lower surfaces of the cell at a central point. Thus, an averaged value for the ratio between the width and the thickness was determined in sham ENDO (0.67 \pm 0.02$)$, sham EPI $(0.68 \pm 0.01)$, PMI ENDO (0.66 \pm 0.02$)$, and PMI EPI $(0.67 \pm 0.02)(n=40$ cells in each group).

After a test activation at $\mathrm{pCa} 4.5$, the cell was sequentially stretched in relaxing solution to 1.9, 2.1, and $2.3 \mu \mathrm{m}$ SL using a stepper motor driven micromanipulator at a speed of 0.1 length.sec ${ }^{-1}$ to evaluate steady-state passive tension. Force-pCa relationships were established at two SL, 1.9 and $2.3 \mu \mathrm{m}$. Active forces at submaximal activations were normalized to maximal tension ( $\mathrm{pCa}$ 4.5) at the same SL. The relation between force and $\mathrm{pCa}$ was fitted to the following equation: force $=\left[\mathrm{Ca}^{2+}\right]^{\mathrm{nH}} /\left(\mathrm{K}+\left[\mathrm{Ca}^{2+}\right]^{\mathrm{nH}}\right)$, where $\mathrm{n}_{\mathrm{H}}$ is the Hill coefficient and $\mathrm{pCa}$, $\mathrm{pCa}$ for half-maximal activation, equals $-(\log \mathrm{K}) / \mathrm{n}_{\mathrm{H}}$.

\section{Biochemical analysis of titin}

Skinned myocardial strips were pulverized in liquid nitrogen and solubilized for $3 \mathrm{~min}$ at $60^{\circ} \mathrm{C}$ in Laemmli buffer. A batch of cells used for mechanical experiments was also solubilized at the end of the day. The samples were analyzed with SDS-PAGE (2.5-7\% acrylamide gradient gels) (19). After electrophoretic separation gels were stained with $0.1 \%$ Coomassie blue G 250 . Wet gels were acquired with an imaging system (Kodak Image Station 2000R). Images were analyzed using Kodak 1D image analysis software. 


\section{Immunoblots}

Freshly dissected skinned strips, maintained at slack length or stretched by $\sim 20-30 \%$ of initial slack length to $2.30 \pm 0.05 \mu \mathrm{m}$ SL for $1 \mathrm{~min}$, were quick-frozen, then homogenized in ice-cold trichloroacetate $(10 \%)$. This allows for keeping the phosphorylation status of proteins. Samples were then washed three times in acetone $/ 10 \mathrm{mM}$ DTT. The pellet was mixed with urea buffer (in M: urea 8, DTT 0.5, Tris 0.22, glycin 0.25, saturated glucose, EDTA 0.4, PMSF 5.10 ${ }^{-4}$, NaF 0.35 ) (21). Twenty micrograms of extracted proteins were separated either on $15 \%$ SDS-PAGE for TnI analysis or 10\% urea gel for MLC2 isoforms (21) and blotted onto nitrocellulose membrane (Protran, Schleichen and Schuele, Dassel, Germany). For both studies, all samples from one animal were always loaded on the same gel. MLC2 isoforms were specifically detected with a cardiac MLC2 antibody (Coger SA, Paris, France). Total TnI content was determined on the first wells of the membrane with a total cardiac TnI antibody (clone 6F9, Hytest, Turku, Finland) and the protein kinase A phosphorylated form of cardiac TnI antibody on the other wells (clone 5E6, Hytest). Immunodetection was revealed with ECL Plus system (Amersham Pharmacia, Little Chalfont Buckinghamshire, England). Results were expressed relative to the total amount of the detected protein.

\section{Data analysis and statistical methods}

Data are presented as mean \pm SE ( $n=$ number of cells studied). One-way or two-way ANOVA was applied for comparison between different groups (as appropriate). When significant interactions were found, a Holm-Sidak $t$ test was applied (Sigmastat3 software), with $P<0.05$.

\section{RESULTS}

\section{Length-dependent contractile properties across the left ventricular wall}

Skinned cells isolated from sham and PMI EPI and ENDO heart layers were maintained in isometric conditions. Active force was generated by superfusing cells with various $\mathrm{Ca}^{2+}$ containing solutions (Fig. 1). Myofilament sensitivity to $\mathrm{Ca}^{2+}\left(\mathrm{pCa}_{50}\right)$ established at $1.9 \mu \mathrm{m}$ SL was not significantly different between cell layers and between sham and PMI animals (Table 1). Stretching sham cells induced a leftward shift of the tension-pCa curve $\left(\Delta \mathrm{pCa}_{50}\right)$ that was more pronounced in the ENDO cells $(0.24 \pm 0.02$ pCa unit, $n=10)$ compared with EPI cells $(0.11 \pm 0.01$, $n=10$ ). However, this difference disappeared in PMI hearts where $\Delta \mathrm{pCa}_{50}$ values obtained in EPI and ENDO cells were identical $(0.14 \pm 0.01 \mathrm{pCa}$ unit, $n=8$ and 11 cells, respectively). The reduced ENDO-PMI stretch-sensitization compared with ENDO-sham indicates that myocardial infarction affects the regulation of cellular contractility predominantly in the endocardial layer. Maximal active tension and Hill coefficient were not significantly different between the various groups.

\section{Passive properties of control and PMI cardiomyocytes}

Cellular stiffness of each cell was measured by gradual stretch from slack length (measured before attachment) to 1.9, 2.1, and $2.3 \mu \mathrm{m}$ SL. In sham hearts, ENDO cells developed significantly higher passive tension when stretched to $2.3 \mu \mathrm{m}$ SL than EPI cells (Fig. $2 A)$. This gradient of stiffness was maintained in PMI tissues. Over the physiological operating range of $\mathrm{SL}$, titin is essentially responsible for the cellular passive properties (22). Rat ventricles express 
mostly the short titin isoform (19). However, muscle stiffness can be modulated by differential expression of titin isoforms in physiological $(19)$ and pathological conditions $(23,24)$ but also by varying titin content within the sarcomere (25). Variation of titin content and isoforms with localization and disease was investigated. In control conditions, the migration of titin revealed a major T1 band corresponding to full-length titin associated with a lower band, T2 resulting from an alteration of titin filament (Fig. 2) as reported previously (22). No change in titin isoform was observed across the sham and PMI ventricles (Fig. 2B, $2 \mathrm{C}$ inset). However, the amount of titin relative to myosin varied with localization (Fig. 2C). The ratio was lower in EPI (0.22 \pm 0.02$)$ than in ENDO $(0.31 \pm 0.02)$ sham cells. A similar trend was observed in PMI rats between EPI $(0.26 \pm 0.02)$ and ENDO $(0.34 \pm 0.03)$ tissues.

\section{Transmural gradient of passive tension-dependent contractile properties}

It has been proposed that $\Delta \mathrm{pCa}_{50}$ is closely correlated to titin-based passive tension rather than to $\mathrm{SL}(4,6)$. We thus studied the relationship between $\Delta \mathrm{pCa}_{50}$ and the passive tension developed at $2.3 \mu \mathrm{m}$ SL. Figure 3 represents the average values of $\Delta \mathrm{pCa}_{50}$ established in cells isolated from sham and PMI rats, taking into account their location in the left ventricular free wall. Passive tension ranged from $\sim 3-9 \mathrm{mN} / \mathrm{mm}^{2}$ and $\Delta \mathrm{pCa}_{50}$ from $0.08-0.30 \mathrm{pCa}$ unit. We found a positive correlation between titin-based passive tension and $\mathrm{Ca}^{2+}$ sensitivity of activation. As previously reported in intact cells (18), EPI cells were more compliant and the SL-dependent sensitization of activation was less effective than in ENDO cells. Mid-myocardial (MID) cells demonstrated intermediate properties. This representation demonstrates a gradient of passive and active properties across the left ventricular free wall. More interestingly, we observed that this positive correlation was abolished after myocardial infarction due to a diminished $\Delta \mathrm{pCa}_{50}$ of ENDO cells. The gradient of stiffness was unchanged, but the length sensitization of activation of ENDO-PMI cells was significantly reduced compared with ENDO-sham cells. When the SL dependence of

$\mathrm{Ca}^{2+}$ sensitivity was indexed by $\Delta\left[\mathrm{Ca}^{2+}\right]_{50}$ (i.e., difference in $\left[\mathrm{Ca}^{2+}\right]_{\text {i }}$ required for half-maximal activation at 1.9 and $2.3 \mu \mathrm{m} \mathrm{SL}$ ), similar correlations were obtained (data not shown). Note that passive tension of both EPI and ENDO-PMI cells was much more variable than of sham ones, most probably indicating remodeling of myocardial tissue. However one cannot fully exclude that cell isolation from the two layers was more difficult due to wall thinning. For the latter reason, we were not able to properly isolate MID cells from PMI hearts.

\section{Phosphorylation of thin and thick filament regulatory proteins}

Disappearance of the gradient of stretch-induced increase in $\mathrm{Ca}^{2+}$ sensitivity in PMI cells suggests an alteration in the biomechanical sensing pathway(s) in diseased rats. Taking into account that the gradient of passive tension is maintained in PMI hearts, we hypothesized that stretch-induced physical rearrangement process was not primarily affected. We thus measured before and after 1-min stretch of skinned myocardial strips, the state of phosphorylation of troponin I and of the two ventricular isoforms of MLC2, a thin and thick regulatory protein, respectively. TnI phosphorylation by PKA is well known to affect $\mathrm{Ca}^{2+}$ sensitivity and was proposed to enhance length-dependent activation (8). Using a specific antibody that recognized the PKA-phosphorylated TnI, we determined TnI phosphorylation levels in EPI and ENDO layers of sham and PMI hearts. TnI content and its phosphorylation level were similar between regions of both sham and PMI rats and were unaffected by stretch (i. $\underline{\text { Fig. }})$. 
Phosphorylation of MLC2 has been previously shown to induce a leftward shift of the tension$\mathrm{pCa}$ curves in cardiac muscles (26). In addition, MLC2 phosphorylation is not homogeneous within the whole heart (27). We thus hypothesized that MLC2 phosphorylation could be induced by a stretch-dependent mechanism tuned across the wall, resulting in a gradient of activation. Four bands were detected corresponding to the two ventricular isoforms of VLC2 (VLC2a and VLC2b) and their phosphorylated forms (P-VLC2a and P-VLC2b) as already described using 2D gel electrophoresis $(14,28,29)$. Phosphorylation level of VLC2a was significantly lower in ENDO-PMI compared with ENDO-sham tissues, and was unaffected by stretch in any of the studied groups. VLC2b phosphorylation was similar in EPI-sham and PMI tissues, and independent of stretch. Interestinglyl in ENDO-sham tissues, VLC2b phosphorylation was hardly detectable at rest, but was increased sixfold by stretch. This stretch-dependent phosphorylation of VLC2b was lost in ENDO-PMI cells (ig. 4B).

\section{DISCUSSION}

For a better understanding of the molecular mechanisms that underlie the Frank-Starling relationship, the goal of this study was to characterize the length-dependent contractile properties of cardiomyocytes isolated from control and failing animals, taking into account their localization within the left ventricular wall. The present work confirms the observation that $\mathrm{Ca}^{2+}$ sensitivity of the contractile machinery is more correlated to stretch-induced modification in passive tension than to SL. Further, it demonstrates for the first time the existence of a gradient of passive tension-dependent $\mathrm{Ca}^{2+}$ sensitivity of the contractile machinery within the left ventricular wall accompanied by a marked passive tension-dependent increase in VLC2 phosphorylation of ENDO cells. Following myocardial infarction, this transmural gradient of passive tension-dependent $\mathrm{Ca}^{2+}$ sensitivity is lost together with the passive tension-induced MLC2 phosphorylation. The remaining component of length-dependent $\mathrm{Ca}^{2+}$ sensitization is similar to that seen in control or diseased epicardium (Fig. 5).

\section{Transmural contractile properties and passive tension rather than length dependence of force}

Here, we report that both passive and active contractile properties follow a positive gradient from epicardium toward endocardium. Skinned ENDO cells are stiffer and demonstrate a larger increase in $\mathrm{Ca}^{2+}$ sensitivity following stretch. This is consistent with our previous observations that passive and active tensions measured in intact attached cells are higher in ENDO than in EPI cells (18).

The SL range across the wall and its changes during cardiac cycle are still unknown. It has been proposed however that during filling, the nonuniform transmural SL distribution observed in the unloaded state becomes more uniform, with the inner sarcomeres elongating more than the outer ones (30). This is in accordance with higher circumferential strains and ejection fraction observed in vivo in the endocardium (31). In line with these observations, our study shows that heterogeneous cellular mechanical properties may contribute to the nonuniform deformation of the wall. It could also be anticipated that the higher stiffness in the endocardium allows for faster relaxation of this layer during the early diastolic refilling due to titin-based restoring force (32).

Furthermore, $\Delta \mathrm{pCa}_{50}$ is more closely correlated to passive tension than to SL. This has been initially demonstrated by degrading titin with a mild trypsin treatment (4) and confirmed later on 
in other animal species coexpressing various titin isoforms or by varying prehistory of stretch before activation $(5,6)$. Note that despite the use of different species, mouse (5) or bovine (6), similar $\Delta \mathrm{pCa}_{50}$-passive tension relations were found. Such a correlation between $\Delta \mathrm{pCa}_{50}$ and cell stiffness was also observed in this study in the sham rat heart. Differences in cell compliance could not be explained by cross-bridge-dependent passive tension because they were also seen in the presence of 2,3-butadione monoxime (data not shown). Titin isoform switch was not detected across the left ventricular wall to explain the stiffness gradient, but instead we noticed differential titin amount, with stiffer ENDO cells expressing more titin per half-sarcomere than EPI cells. The difference in stiffness across the free wall seems to be essentially a titin-based mechanism, because we observed that degradation of titin with mild trypsin treatment in both sham and PMI homogenizes passive tension across the wall to $\sim 2 \mathrm{mN} / \mathrm{mm}^{2}$ (data not shown). From this study, we cannot however exclude that other mechanisms may participate in the passive tension modulation across the wall such as PKA phosphorylation, titin-actin interaction, $\mathrm{Ca}^{2+}$ binding for titin-based modulation (24), or a difference in myofibrillar area between EPI and ENDO cells.

\section{Stretch-induced phosphorylation of the regulatory MLC2}

Titin has been proposed to be involved in the Frank-Starling mechanism at least by reducing the interfilament lattice spacing $(5,6)$. In addition, stretch-dependent structural changes in the thick filaments in response to passive stretch has been proposed for cardiac muscle $(4,33)$. Indeed, stretch-dependent activation of the cardiac sarcomere cannot solely be explained by lattice spacing, implying other modulation pathways (34). Therefore, we postulated that in ENDO cells a passive tension-induced signaling pathway is tuned by stretch, on top of the length-induced effect that could be explained by a change in interfilament lattice spacing. It has recently been suggested that the phosphorylation level of cTnI (on PKA sites) regulates length dependence of activation (8). This hypothesis would imply a dephosphorylation of TnI with stretch to account for increased activation. Under our experimental conditions, cTnI phosphorylation was similar in both EPI and ENDO cells and was not affected by stretch. TnI is known to have specific sites of phosphorylation by PKC that may affect myofibrillar $\mathrm{Ca}^{2+}$ sensibility (35). This latter study did not explore specifically this pathway of phosphorylation of TnI nor the effect of acute stretch. However, we showed previously that incubating myocytes with MLC kinase (MLCK) increases myofibrillar $\mathrm{Ca}^{2+}$ sensitivity. No additional sensitization was observed when myocytes were incubated with both MLCK and PKC simultaneously while TnI is phosphorylated in these conditions (26). This suggests that PKC may increase $\mathrm{Ca}^{2+}$ sensitivity by activating MLCK.

Phosphorylation of the regulatory protein MLC2 by MLCK represents an important and ubiquitous regulatory mechanism to modulate force generation of smooth, skeletal, and cardiac muscles. It has been shown that MLC2 phosphorylation modulates active tension of the whole heart (36). By increasing the population of myosin heads that could interact with actin, MLC2 phosphorylation increases myofibrillar $\mathrm{Ca}^{2+}$ sensitivity $(37,35)$. Based on our previous experience that MLC2 phosphorylation by MLCK sensitizes myofilaments (26), we proposed that stretch could result in MLC2 phosphorylation. We observed here that stretch mostly activates phosphorylation of VLC2b in ENDO cells that have a very low basal phosphorylation level compared with EPI cells (27). The present study did not explore the stretch-dependent mechanisms leading to the increase in VLC2b phosphorylation that can include an activation of MLCK as well as an inhibition of a sustained phosphatase activity. 


\section{Reduction of the stretch-dependent $\mathrm{Ca}^{2+}$ sensitivity in PMI}

The mechanisms underlying the decline in cardiac pump function during cardiac insufficiency are poorly understood. They lead to a gradual increase in left ventricular end-diastolic pressure and a decrease in systolic pressure. The pathological model used in this study was a PMI rat that represents a clinically relevant model, because post-ischemic cardiomyopathy is the major clinical origin of heart failure. Isolated whole heart from this rat model develops a reduced Frank-Starling relationship. At the cellular level, mechanical behavior of the epicardium seems unaffected. ENDO cells exhibit a markedly reduced stretch-dependent activation that occurs without any effect on the $\mathrm{Ca}^{2+}$ sensitivity at resting length $(1.9 \mu \mathrm{m})$ or changes in titin content or isoform expression. The normal, unaffected $\mathrm{Ca}^{2+}$ sensitivity of ENDO- and EPI-PMI cells at 1.9 $\mu \mathrm{m} \mathrm{SL}$ is in accordance with the observations of Anand et al. (11) who observed remodeling of the myocardium up to $6 \mathrm{wk}$ postinfarction, but normal contractile function and intracellular $\mathrm{Ca}^{2+}$ transient in unloaded intact myocytes.

In heart failure, the transition of $\alpha-\mathrm{MHC}$ to $\beta$-MHC isoform was associated with a decrease in the $\mathrm{Ca}^{2+}$ sensitivity of contractile proteins (38). In this study, the electrophoretic method performed was not able to discriminate the $\alpha$ - and $\beta$-isoforms. Considering that the conversion of $\alpha$ - to $\beta$-MHC in a hypothyroid rat model does not significantly change SL dependence of $\mathrm{Ca}^{2+}$ sensitivity (39), such a transition is also unlikely to account for our results either. This idea is also supported by the fact that albeit ATPase is known to be faster in the $\alpha$-MHC than $\beta$-MHC protein, the Frank-Starling relationship is not determined by the cross-bridge detachment (40).

Changes in titin isoform expression have recently been reported in ischemic human and rat tissues (23). N2BA titin overexpression associates with reduced passive tension in diseased human myofibrils. We could not detect any significant N2BA titin expression in sham or PMI rat hearts despite a high titin extraction efficiency compared with the work cited, nor did we observe significant changes in passive tension either in ENDO or in EPI cells after infarction.

In the ENDO-PMI cells, reduction in the stretch-dependent myofilament activation is associated with a lack of VLC2b phosphorylation (Fig. 5). Phosphorylation of both VLC2 isoforms is reduced in PMI rats and particularly the VLC2b isoform does not get phosphorylated following stretch. Decreased phosphorylation of VLC2 had been associated with depressed responsiveness of the contractile apparatus to the activating $\mathrm{Ca}^{2+}$, accounting in part for the severe heart failure of patients in whom both VLC2 isoforms were dephosphorylated (14). Nevertheless, it was mentioned that incubation in cardioplegic solution used to keep human tissues might have dephosphorylated MLC2 as well. Similar dephosphorylation of MLC2, in particular VLC2a, was also observed in diseased human tissues and was then correlated with increased contractility of myocytes $(15,29)$. As indicated by the authors, this result is rather surprising considering that MLCK increases $\mathrm{Ca}^{2+}$ sensitivity of myofilaments $(26,35)$.

The reduced stretch-dependent contractile properties and VLC2 phosphorylation seen in the ENDO-PMI cells supports the hypothesis that MLC2 is actively involved in the stretch-sensing regulation of contractility. This conclusion, however, does not rule out the participation of other contractile proteins such as MHC, TnI, or TnC in the modulation of contractility. To this point, in ENDO-control cells, the regulation of contractility involves a complex cascade in which titin seems to act as a crucial upstream link. This is supported by the observations that after mild trypsination (4) of both EPI and ENDO cells from sham and PMI rats to degrade titin until 
passive tension reaches $\sim 2 \mathrm{mN} / \mathrm{mm}^{2}, \Delta \mathrm{p}_{\text {Ca50 }}$ was decreased to $\sim 0.1 \mathrm{U}$ similarly in all four cell types (unpublished data).

We thus demonstrate that increasing passive tension by stretching titin modulates the myofibrillar sensitivity for $\mathrm{Ca}^{2+}$ by, yet unidentified, mechanisms that lead to VLC2 phosphorylation. It has been proposed for striated and smooth muscles that MLC phosphorylation could move the S1 subfragment of myosin away from the thick-filament backbone and modulate the actomyosin interaction (41). Such a mechanism could be related to observations, in skeletal muscle, that stretch induces structural changes in the thick filament that lead to an increase in the fraction of cross-bridges in the disordered state (42). In cardiac tissue, mainly ENDO cells, the signal transduction pathway that determines passive tension-based modulation of actomyosin interaction has yet to be analyzed.

In conclusion, nonuniformity is a major characteristic of the normal adult left ventricle (LV). The heterogeneous myocardial deformation pattern might be caused not only by the morphological heterogeneity of the tissue in the LV wall, but also by the nonuniform contractile properties of the myocytes across the wall. The loss of a contractile transmural gradient after myocardial infarction should contribute to the impaired LV function.

\section{ACKNOWLEDGMENTS}

This work was supported in part by Association Française contre les Myopathies, Fondation pour la Recherche Médicale, Fondation de France, Fondation Simone Del Duca, and Conseil Régional du Languedoc-Roussillon. SS held a Eurogendis Marie Curie grant fellowship. We thank Patrice Bideaux and Guillermo Salazar for technical assistance and Drs. A. Lazou, A. Siamkouri, and H. Viko for preliminary experiments.

\section{REFERENCES}

1. Lakatta, E. G. (1992) Length modulation of muscle performance. Frank-Starling law of the heart. In The Heart and Cardiovascular System (H.A., Fozzard, et al., eds) pp. 1325-1351, Raven Press, New York

2. Fuchs, F., and Wang, Y. P. (1996) Sarcomere length versus interfilament spacing as determinants of cardiac myofilament $\mathrm{Ca} 2+$ sensitivity and $\mathrm{Ca} 2+$ binding. J. Mol. Cell. Cardiol. 28, 1375-1383

3. Cazorla, O., Pascarel, C., Garnier, D., and Le Guennec, J. Y. (1997) Resting tension participates in the modulation of active tension in isolated guinea pig ventricular myocytes. J. Mol. Cell. Cardiol. 29, 1629-1637

4. Cazorla, O., Vassort, G., Garnier, D., and Le Guennec, J. Y. (1999) Length modulation of active force in rat cardiac myocytes: is titin the sensor? J. Mol. Cell. Cardiol. 31, 1215-1227

5. Cazorla, O., Wu, Y., Irving, T. C., and Granzier, H. (2001) Titin-based modulation of calcium sensitivity of active tension in mouse skinned cardiac myocytes. Circ. Res. 88, 1028-1035 
6. Fukuda, N., Wu, Y., Farman, G., Irving, T. C., and Granzier, H. (2003) Titin isoform variance and length dependence of activation in skinned bovine cardiac muscle. J. Physiol. 553, $147-154$

7. Konhilas, J. P., Irving, T. C., de Tombe, P. P., Konhilas, J., Perry, D., and Fischetti, R. (2002) Myofilament calcium sensitivity in skinned rat cardiac trabeculae: role of interfilament spacing. Circ. Res. 90, 59-65

8. Konhilas, J. P., Irving, T. C., Wolska, B. M., Jweied, E. E., Martin, A. F., Solaro, R. J., and de Tombe, P. P. (2003) Troponin I in the murine myocardium: influence on lengthdependent activation and interfilament spacing. J. Physiol. 547, 951-961; Epub Jan 24, 2003

9. Holubarsch, C., Ruf, T., Goldstein, D. J., Ashton, R. C., Nickl, W., Pieske, B., Pioch, K., Ludemann, J., Wiesner, S., Hasenfuss, G., et al. (1996) Existence of the Frank-Starling mechanism in the failing human heart. Investigations on the organ, tissue, and sarcomere levels. Circulation 94, 683-689

10. Schwinger, R. H., Bohm, M., Koch, A., Schmidt, U., Morano, I., Eissner, H. J., Uberfuhr, P., Reichart, B., and Erdmann, E. (1994) The failing human heart is unable to use the FrankStarling mechanism. Circ. Res. 74, 959-969

11. Anand, I. S., Liu, D., Chugh, S. S., Prahash, A. J., Gupta, S., John, R., Popescu, F., and Chandrashekhar, Y. (1997) Isolated myocyte contractile function is normal in postinfarct remodeled rat heart with systolic dysfunction. Circulation 96, 3974-3984

12. de Tombe, P. P. (1998) Altered contractile function in heart failure. Cardiovasc. Res. 37, $367-380$

13. Margossian, S. S., White, H. D., Caulfield, J. B., Norton, P., Taylor, S., and Slayter, H. S. (1992) Light chain 2 profile and activity of human ventricular myosin during dilated cardiomyopathy. Identification of a causal agent for impaired myocardial function. Circulation 85, 1720-1733

14. Morano, I., Lengsfeld, M., Ganten, U., Ganten, D., and Ruegg, J. C. (1988) Chronic hypertension changes myosin isoenzyme pattern and decreases myosin phosphorylation in the rat heart. J. Mol. Cell. Cardiol. 20, 875-886

15. van der Velden, J., Papp, Z., Boontje, N. M., Zaremba, R., de Jong, J. W., Janssen, P. M., Hasenfuss, G., and Stienen, G. J. (2003) The effect of myosin light chain 2 dephosphorylation on $\mathrm{Ca} 2+$-sensitivity of force is enhanced in failing human hearts. Cardiovasc. Res. 57, 505-514

16. Liu, X., Shao, Q., and Dhalla, N. S. (1995) Myosin light chain phosphorylation in cardiac hypertrophy and failure due to myocardial infarction. J. Mol. Cell. Cardiol. 27, 2613-2621

17. Aimond, F., Alvarez, J. L., Rauzier, J. M., Lorente, P., and Vassort, G. (1999) Ionic basis of ventricular arrhythmias in remodeled rat heart during long-term myocardial infarction. Cardiovasc. Res. 42, 402-415 
18. Cazorla, O., Le Guennec, J. Y., and White, E. (2000) Length-tension relationships of subepicardial and sub-endocardial single ventricular myocytes from rat and ferret hearts. J. Mol. Cell. Cardiol. 32, 735-744

19. Cazorla, O., Freiburg, A., Helmes, M., Centner, T., McNabb, M., Wu, Y., Trombitas, K., Labeit, S., and Granzier, H. (2000) Differential expression of cardiac titin isoforms and modulation of cellular stiffness. Circ. Res. 86, 59-67

20. Cazorla, O., Lacampagne, A., Fauconnier, J., and Vassort, G. (2003) SR33805, a Ca2+ antagonist with length-dependent $\mathrm{Ca} 2+-$-sensitizing properties in cardiac myocytes. $\mathrm{Br} . \mathrm{J}$. Pharmacol. 139, 99-108

21. Hathaway, D. R., and Haeberle, J. R. (1985) A radioimmunoblotting method for measuring myosin light chain phosphorylation levels in smooth muscle. Am. J. Physiol. 249, C345C351

22. Granzier, H. L., and Irving, T. C. (1995) Passive tension in cardiac muscle: contribution of collagen, titin, microtubules, and intermediate filaments. Biophys. J. 68, 1027-1044

23. Neagoe, C., Kulke, M., del Monte, F., Gwathmey, J. K., de Tombe, P. P., Hajjar, R. J., and Linke, W. A. (2002) Titin isoform switch in ischemic human heart disease. Circulation 106, 1333-1341

24. Granzier, H. L., and Labeit, S. (2004) The giant protein titin: a major player in myocardial mechanics, signaling, and disease. Circ. Res. 94, 284-295

25. Toursel, T., Stevens, L., Granzier, H., and Mounier, Y. (2002) Passive tension of rat skeletal soleus muscle fibers: effects of unloading conditions. J. Appl. Physiol. 92, 1465-1472

26. Clement, O., Puceat, M., Walsh, M. P., and Vassort, G. (1992) Protein kinase C enhances myosin light-chain kinase effects on force development and ATPase activity in rat single skinned cardiac cells. Biochem. J. 285, 311-317

27. Davis, J. S., Hassanzadeh, S., Winitsky, S., Lin, H., Satorius, C., Vemuri, R., Aletras, A. H., Wen, H., and Epstein, N. D. (2001) The overall pattern of cardiac contraction depends on a spatial gradient of myosin regulatory light chain phosphorylation. Cell 107, 631-641

28. van der Velden, J., Boontje, N. M., Papp, Z., Klein, L. J., Visser, F. C., de Jong, J. W., Owen, V. J., Burton, P. B., and Stienen, G. J. (2002) Calcium sensitivity of force in human ventricular cardiomyocytes from donor and failing hearts. Basic Res. Cardiol. 97, I118-I126

29. van der Velden, J., Papp, Z., Zaremba, R., Boontje, N. M., de Jong, J. W., Owen, V. J., Burton, P. B. J., Goldmann, P., Jaquet, K., and Stienen, G. J. M. (2003) Increased Ca2+sensitivity of the contractile apparatus in end-stage human heart failure results from altered phosphorylation of contractile proteins. Cardiovasc. Res. 57, 37-47

30. Rodriguez, E. K., Omens, J. H., Waldman, L. K., and McCulloch, A. D. (1993) Effect of residual stress on transmural sarcomere length distributions in rat left ventricle. Am. J. Physiol. 264, H1048-H1056 
31. Bogaert, J., and Rademakers, F. E. (2001) Regional nonuniformity of normal adult human left ventricle. Am. J. Physiol. Heart Circ. Physiol. 280, H610-H620

32. Helmes, M., Trombitas, K., and Granzier, H. (1996) Titin develops restoring force in rat cardiac myocytes. Circ. Res. 79, 619-626

33. Fukuda, N., Sasaki, D., Ishiwata, S., and Kurihara, S. (2001) Length dependence of tension generation in rat skinned cardiac muscle: role of titin in the frank-starling mechanism of the heart. Circulation 104, 1639-1645

34. Moss, R. L., and Fitzsimons, D. P. (2002) Frank-starling relationship: long on importance, short on mechanism. Circ. Res. 90, 11-13

35. Pi, Y., Zhang, D., Kemnitz, K. R., Wang, H., and Walker, J. W. (2003) Protein kinase C and A sites on troponin I regulate myofilament $\mathrm{Ca} 2+$ sensitivity and ATPase activity in the mouse myocardium. J. Physiol. 552, 845-857

36. Kopp, S. J., and Barany, M. (1979) Phosphorylation of the 19,000-dalton light chain of myosin in perfused rat heart under the influence of negative and positive inotropic agents. $J$. Biol. Chem. 254, 12007-12012

37. Craig, R., Padron, R., and Kendrick-Jones, J. (1987) Structural changes accompanying phosphorylation of tarantula muscle myosin filaments. J. Cell Biol. 105, 1319-1327

38. Metzger, J. M., Wahr, P. A., Michele, D. E., Albayya, F., and Westfall, M. V. (1999) Effects of myosin heavy chain isoform switching on $\mathrm{Ca} 2+$-activated tension development in single adult cardiac myocytes. Circ. Res. 84, 1310-1317

39. Akella, A. B., Ding, X. L., Cheng, R., and Gulati, J. (1995) Diminished Ca2+ sensitivity of skinned cardiac muscle contractility coincident with troponin T-band shifts in the diabetic rat. Circ. Res. 76, 600-606

40. Wannenburg, T., Janssen, P. M., Fan, D., and de Tombe, P. P. (1997) The Frank-Starling mechanism is not mediated by changes in rate of cross-bridge detachment. Am. J. Physiol. 273, $\mathrm{H} 2428-\mathrm{H} 2435$

41. Sweeney, H. L., Bowman, B. F., and Stull, J. T. (1993) Myosin light chain phosphorylation in vertebrate striated muscle: regulation and function. Am. J. Physiol. 264, C1085-C1095

42. Wakabayashi, K., Sugimoto, Y., Tanaka, H., Ueno, Y., Takezawa, Y., and Amemiya, Y. (1994) X-ray diffraction evidence for the extensibility of actin and myosin filaments during muscle contraction. Biophys. J. 67, 2422-2435

Received April 26, 2004; accepted September 9, 2004. 


\section{Table 1}

\section{Regional mechanical characteristics and $\mathrm{Ca}^{2+}$ sensitivity of skinned cardiomyocytes isolated from sham and post-myocardial infarction (PMI) rats ${ }^{a}$}

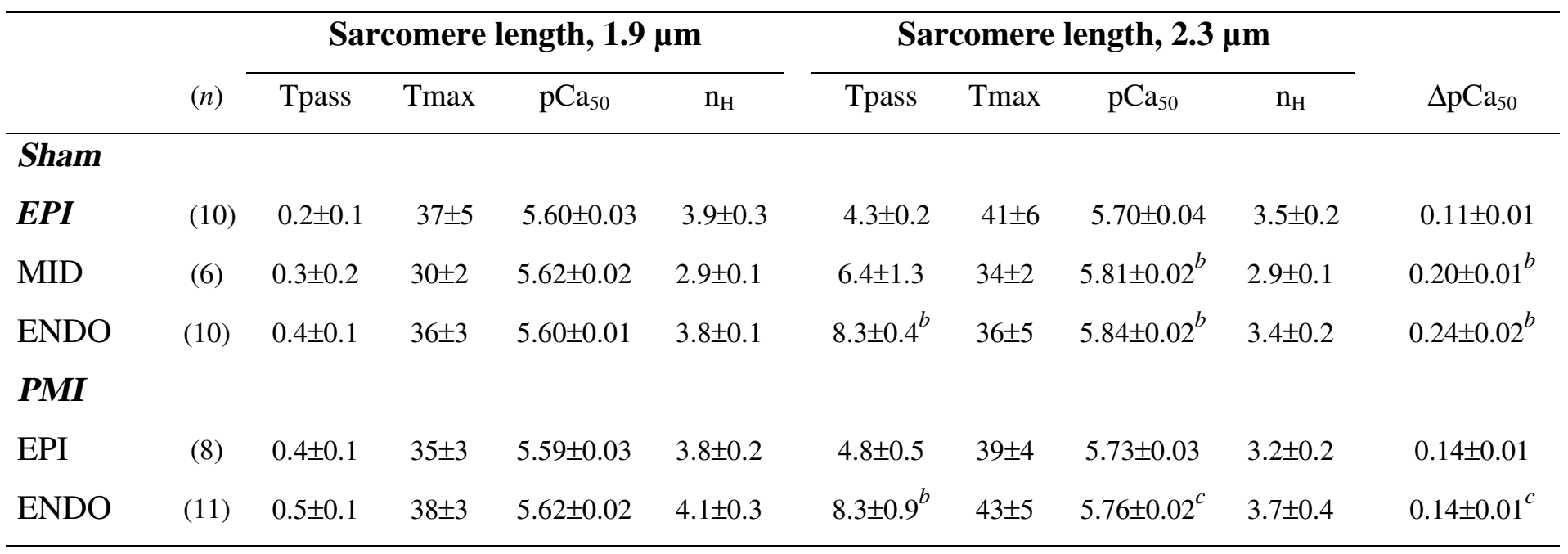

${ }^{a}$ Passive (Tpass) and maximal active (Tmax) tensions in $\mathrm{mN} / \mathrm{mm}^{2}$ were measured at $\mathrm{pCa} 9$ and 4.5 and at 1.9 and $2.3 \mu \mathrm{m}$ sarcomere length, respectively, on sub-epicardial (EPI), mid-wall (MID), and sub-endocardial (ENDO) cells isolated from sham and PMI hearts. Resting sarcomere length before attachment was between 1.82 and $1.88 \mu \mathrm{m}$, similar in cells isolated from sham and PMI hearts and across the ventricular wall. pCa $a_{50}$, pCa for half-maximal activation, and $\mathrm{nH}$, Hill coefficient, were obtained by fitting the force-pCa relations (see Materials and Methods). ${ }^{b}$ EPI vs. ENDO/MID. ${ }^{c}$ ENDO- or EPI-sham vs. ENDO- or EPI-PMI cells. 
Fig. 1

A

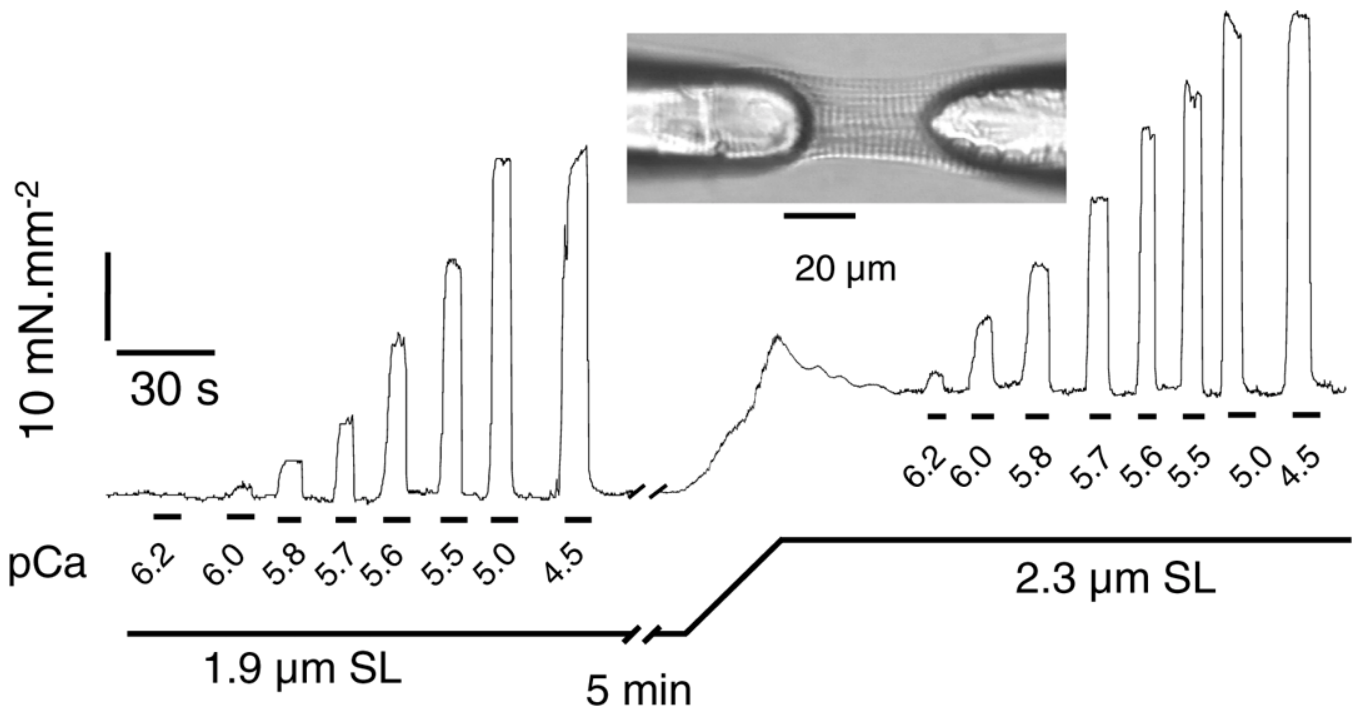

B
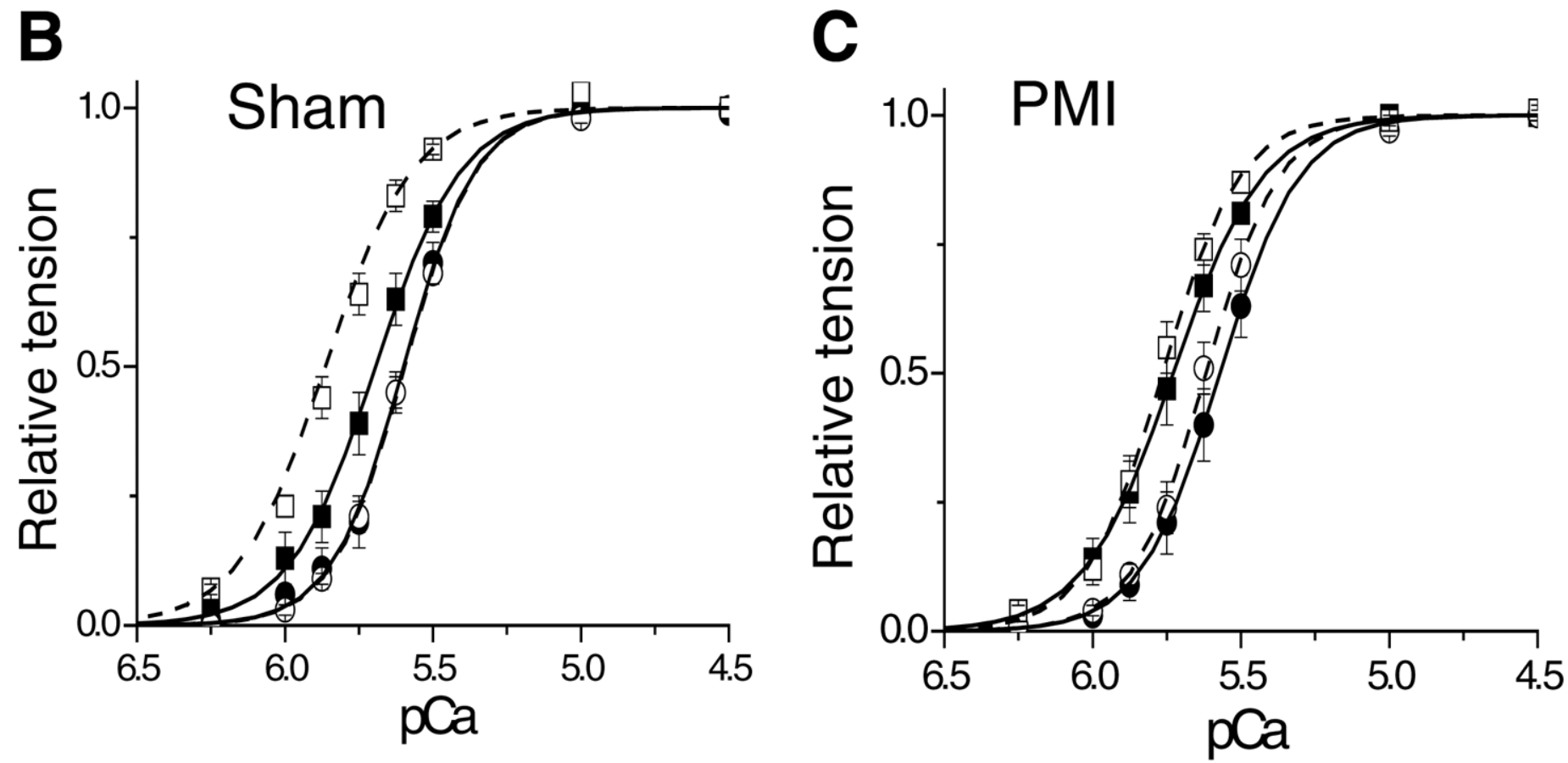

Figure 1. Length dependency of the active tension of isolated skinned cardiomyocytes. $A$ ) Representative measurement of isometric tension elicited on attached skinned cardiomyocyte (inset) at $1.9 \mu \mathrm{m}$ and $2.3 \mu \mathrm{m}$ sarcomere length (SL). Contractions were induced by application of solutions containing various pCa, in the range of 6.2-4.5. $\boldsymbol{B}, \boldsymbol{C}$ ) Tension (normalized to maximal tension)-pCa curves of left ventricular myocytes isolated from sub-epicardial (EPI; ๑, solid line, $n=10$ cells) or sub-endocardial (ENDO; $\square$ O, dashed line, $n=10$ cells) from sham $(\boldsymbol{B})$ and PMI $(\boldsymbol{C})$ rats, were established at two SL: $1.9 \mu \mathrm{m}$ (circle) and $2.3 \mu \mathrm{m}$ (square). Contractile parameters are given in Table 1. 
Fig. 2

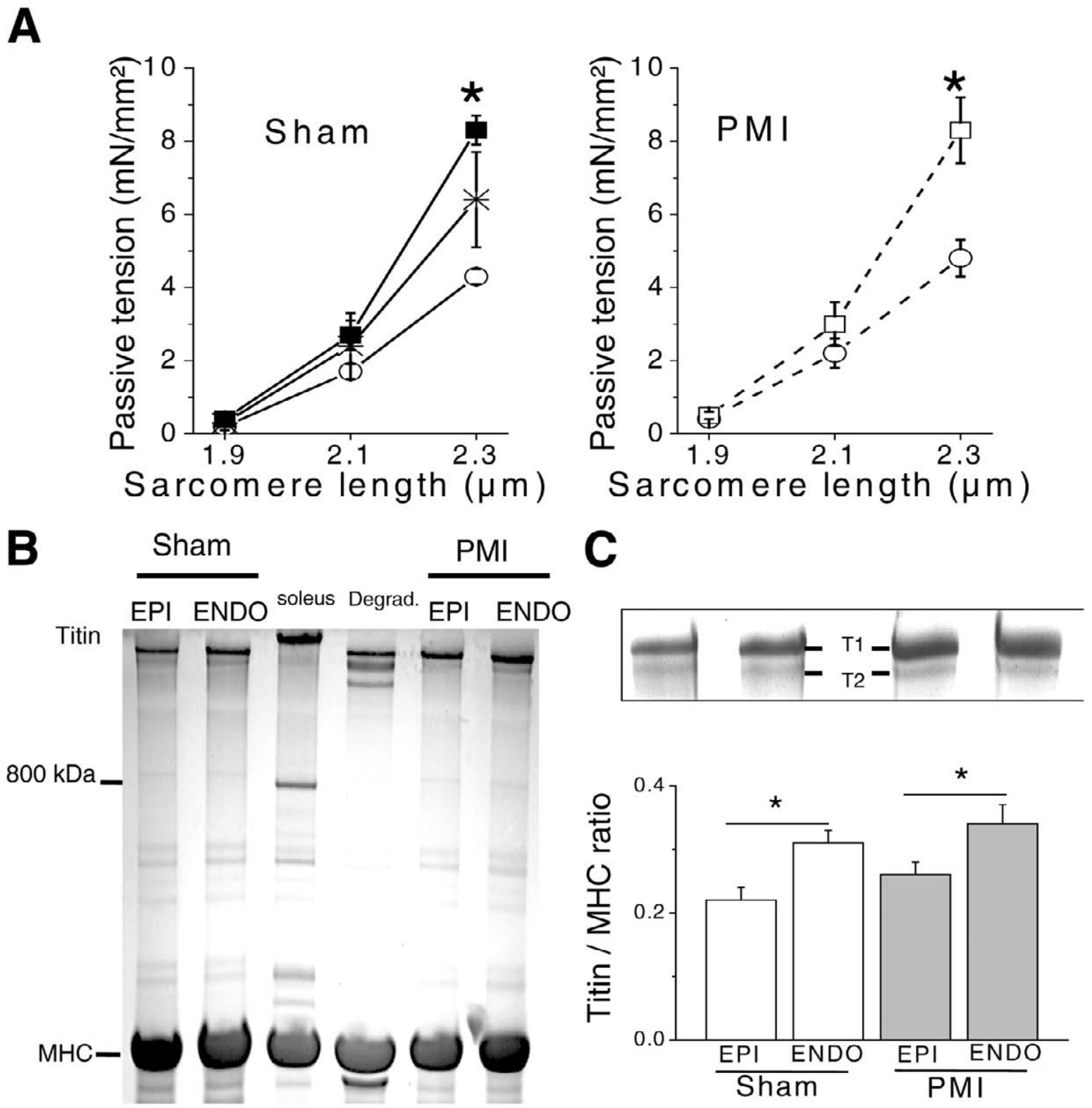

Figure 2. Passive properties of left ventricular isolated skinned myocytes. $\boldsymbol{A}$ ) Steady-state passive tension was measured in relaxing solution ( $\mathrm{pCa} 9$ ) by stretching the skinned cardiomyocyte from 1.9 to 2.1 and $2.3 \mu \mathrm{m}$ sarcomere length (SL). Experiments were performed in ENDO (square) and EPI (circle) cells (same cells as in Fig. 1) and in midwall (star) cells. Passive tension decreased significantly $\left({ }^{*} P<0.05\right)$ in both sham (left panel) and PMI (right panel) cardiomyocytes from ENDO to EPI. B) SDS-PAGE (2.5-7\%) was performed to analyze high molecular weight proteins (titin and MHC). In addition to sham and PMI samples from EPI and ENDO, a skeletal muscle (with a long titin isoform) and a trypsin-treated cardiac tissue (with degradation products of titin) were also loaded. $C$ ) The upper part is an expanded view of a gel showing the two typical forms of titin present in the various samples: T1 (full-length titin) and T2 (first degradation product). No titin isoform change was observed in these conditions (confirmed by anti-N2B and anti-N2A antibodies; data not shown). Optical density (OD) area of titin forms and MHC were analyzed by Gaussian curve fits. To ensure that results were obtained in the linear range of the SDS-PAGE system, we electrophoresed a range of loadings for each sample on the same gel. The OD of titin $(\mathrm{T} 1+\mathrm{T} 2)$ and $\mathrm{MHC}$ were determined for each lane and were plotted vs. their loadings. The slope of the linear range of this relation was determined using linear regression analysis, and the slope ratio of titin and MHC were taken as a measure of the relative amount of titin in the samples. In both PMI and sham, the amount of titin is significantly lower $\left({ }^{*} P<0.05\right)$ in EPI than in ENDO $(n=10$ animals/group). 
Fig. 3

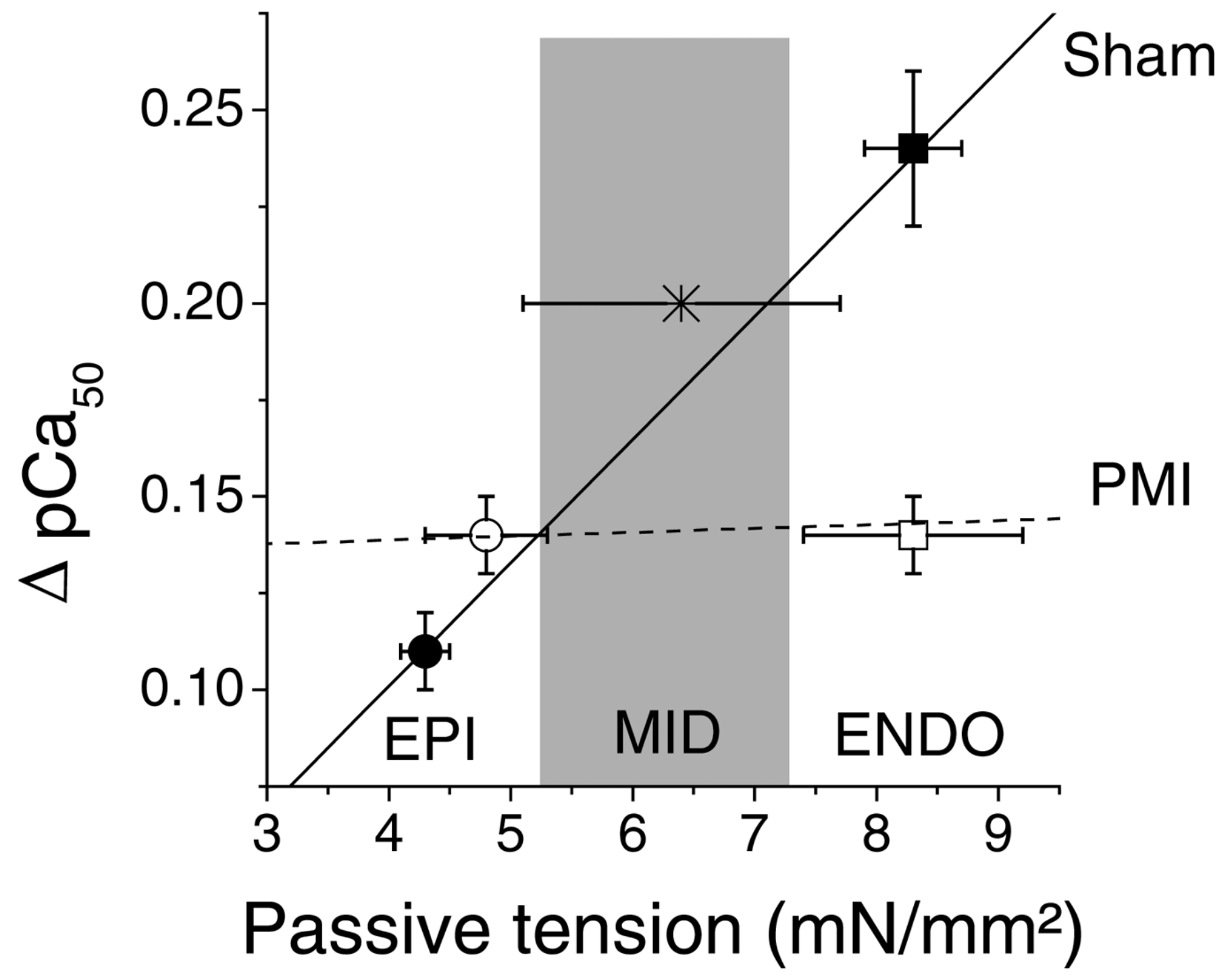

Figure 3. Correlation between passive tension and stretch-induced $\mathrm{Ca}^{2+}$ sensitization across the wall. Data were taken from Figure 1 and Table 1. Variations in $\mathrm{pCa}_{50}$ induced by stretching cells from 1.9 to $2.3 \mu \mathrm{m}$ SL were plotted against mean passive tension for each tissue area. Symbols and error bars correspond to each group of cell (ENDO, $\square$ ( EPI, O•; MID, stari) in sham (closed circle and square) and PMI (open circle and square). Linear regressions were calculated on a scatter plot, including all individual data in sham (slope 3.2 $\pm 0.5, r=0.85$ ) and PMI (slope $0.1 \pm 0.3, r=0.07$ ). 
Fig. 4
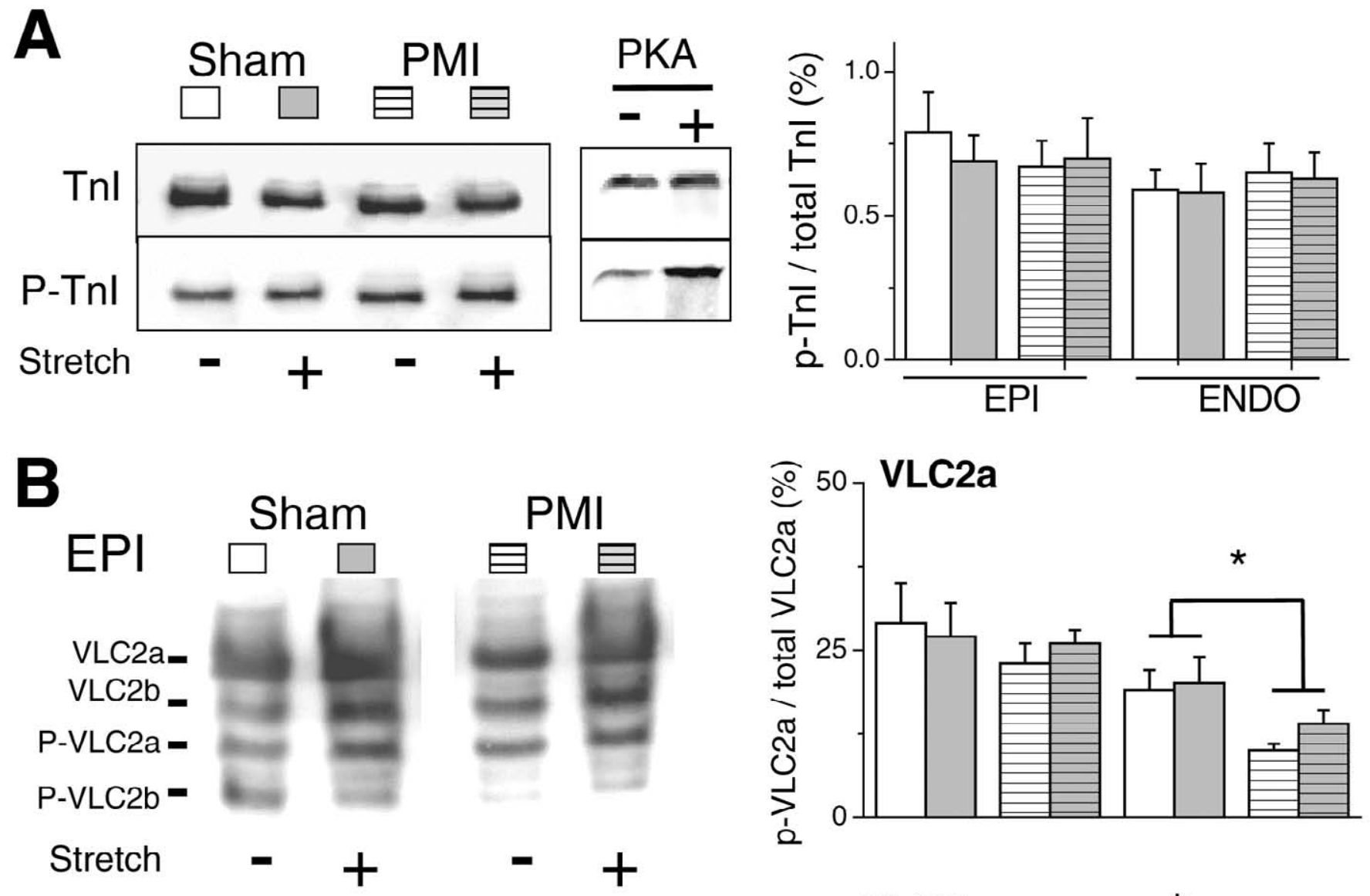
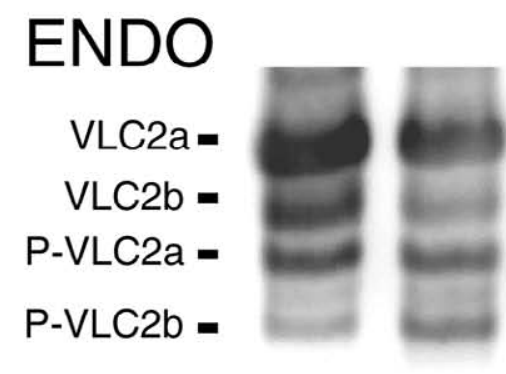

Stretch
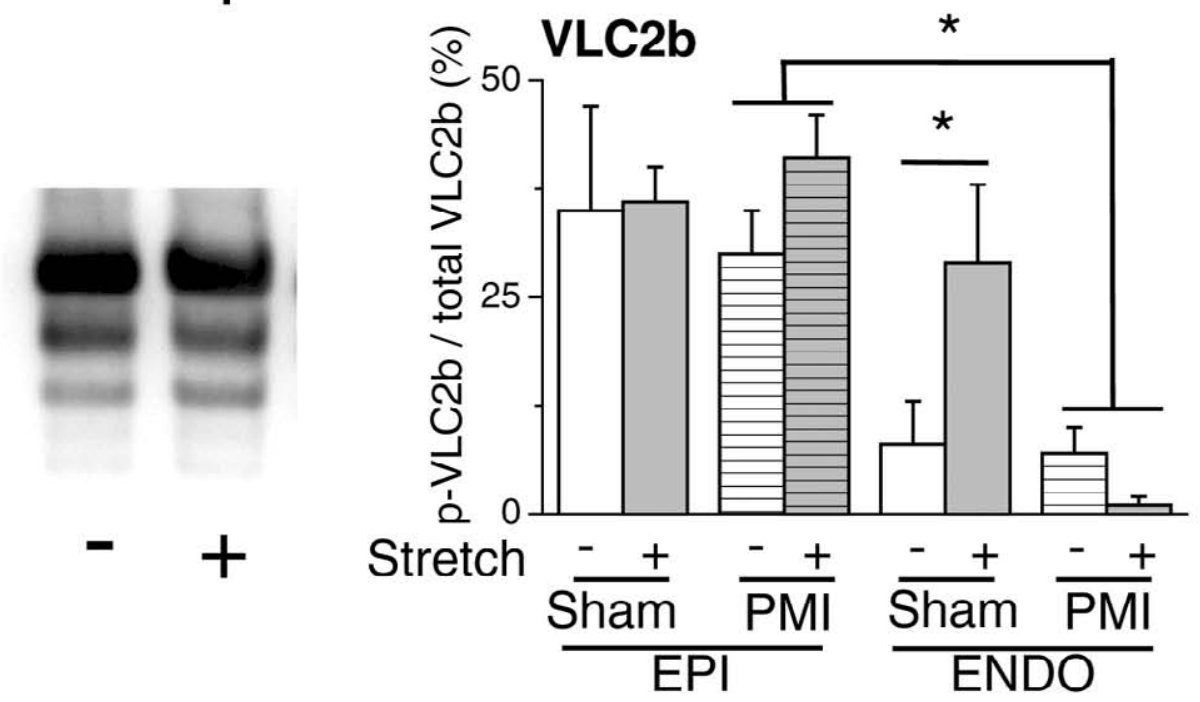

Figure 4. Localized stretch-dependent effect on TnI and MLC2 phosphorylations in control and diseased heart. Immunoblots were performed on permeabilized strips of sham (open column) and PMI (hatched column) myocardium dissected from EPI and ENDO layers before (white) and after (gray)1-min stretch. A) Immunoblots with an anti-cardiac $\mathrm{TnI}$ and anti-cTnI phosphorylated by PKA showed that TnI phosphorylation was unaffected by stretch ( $n=6$ animals/group). The specificity of the anti-phospho TnI was tested on sham cells before and after PKA treatment (right part of the blots). B) Immunoblots (upper panels) show four bands of MLC2 corresponding to the two ventricular isoforms (VLC2a and VLC2b) and their phosphorylated forms (P-VLC2a and P-VLC2b). For phosphorylation quantification, each isoform was separated and expressed as \% of its total amount (phosphorylated + nonphosphorylated forms) for VLC2a and VLC2b. VLC2b is $\sim 30 \%$ of the total amount of MLC2. This form did not vary with localization in sham hearts (34 $\pm 3 \%$ in EPI vs. $29 \pm 2 \%$ in ENDO), whereas it decreased significantly in ENDO $(23 \pm 1 \%)$ compared with EPI-PMI strips $(31 \pm 1 \%)$ ( $n=7$ animals/group). 
Fig. 5
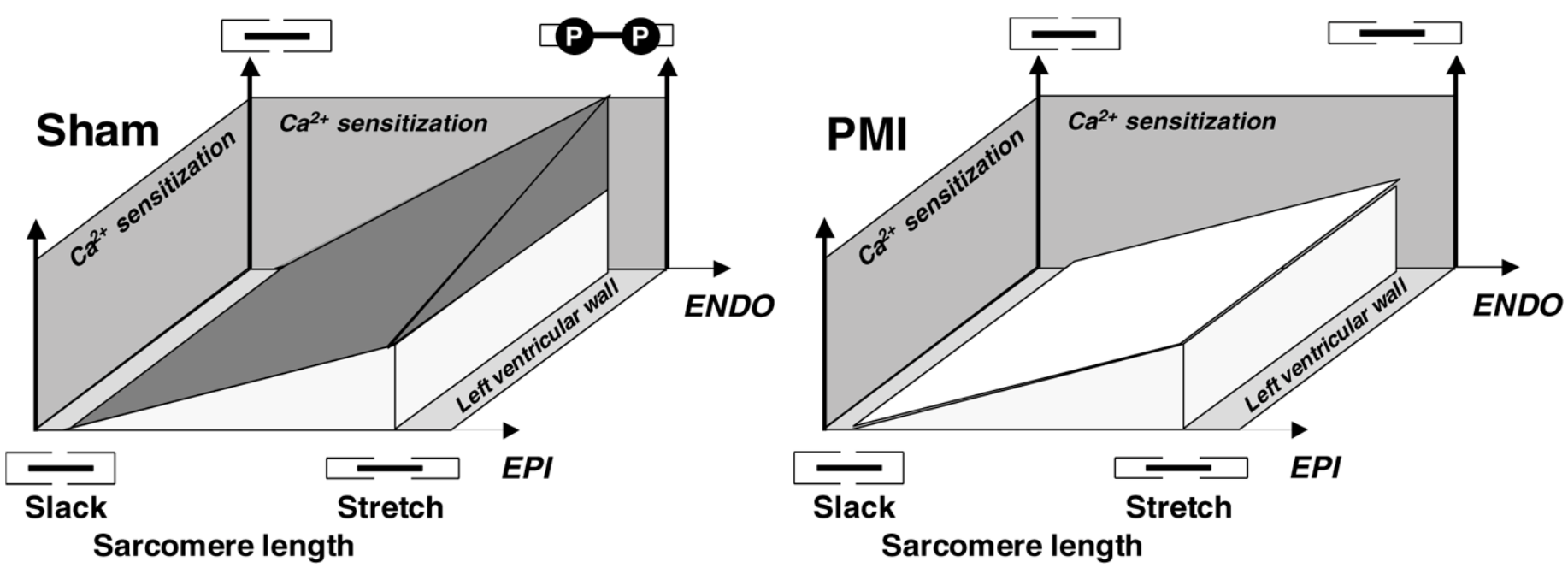

Figure 5. Three-dimensional schematic representation of the stretch-induced $\mathrm{Ca}^{2+}$ sensitization of contractile proteins in sham and post-myocardial infarcted (PMI), sup-epicardial (EPI), and sub-endocardial (ENDO) cells. Note that an EPI to ENDO gradient of $\mathrm{Ca}^{2+}$ sensitization, associated with phosphorylation (gray), occurs only in sham cells, on top of the ubiquitous component of stretch-dependent $\mathrm{Ca}^{2+}$-sensitization (white) seen in both sham and PMI cells. 